\title{
A Behavioral Economic Analysis of Concurrent Ethanol- and Water-Reinforced Responding in Different Preference Conditions
}

\author{
Keith L. Williams and James $H$. Woods
}

\begin{abstract}
Background: The reinforcing properties of orally self-administered drugs have been evaluated by using choice procedures. The preference for the drug over a nondrug alternative has indicated that the drug has greater value than the nondrug alternative as a reinforcer at some drug concentrations. However, at large drug concentrations, the fluid deliveries of the drug may be equal to or less than those of the nondrug alternative, whereas the actual drug intake (milligrams per kilogram of body weight) may continue to increase. In this study, we used behavioral economics to evaluate the reinforcing strength of ethanol in conditions where baseline ethanol fluid deliveries were greater than, equal to, or less than those of the concurrently available water.

Methods: Four male rhesus monkeys were allowed access to ethanol $(2 \%, 8 \%$, or $32 \%)$ and water for 2 $\mathrm{hr} /$ day under a fixed ratio (FR) 4 reinforcement schedule. At each ethanol concentration, the FR for both fluids was gradually increased to FR 64 .

Results: During the FR 4 schedule, the fluid deliveries of ethanol at $2 \%, 8 \%$, and $32 \%$ were greater than, equal to, and less than those of water, respectively. When the FR was increased at $2 \%$ ethanol, fluid deliveries and responding decreased for both the ethanol and water. When the FR was increased at $8 \%$ ethanol, water fluid deliveries and responding decreased more rapidly than did those of ethanol. When the FR was increased at $32 \%$ ethanol, the ethanol fluid deliveries remained the same across all FRs, whereas water fluid deliveries decreased rapidly. At $8 \%$ and $32 \%$ ethanol, the responding for ethanol, relative to water, increased dramatically.

Conclusions: In behavioral economic terms, demand for ethanol was more inelastic regardless of whether the ethanol or water maintained more absolute fluid deliveries at baseline FRs. Therefore, researchers should examine the reinforcing effects of ethanol in a variety of concentration and schedule conditions rather than drawing inferences regarding reinforcing effects simply based on a preference measure.
\end{abstract}

Key Words: Monkeys, Alcohol, Operant Behavior, Choice, Behavioral Economics.

$\mathbf{O}$ NE VIEW OF drug dependence suggests that drug taking is a choice behavior (Jaffe, 1990; Vuchinich and Tucker, 1988). Drug use becomes the highly preferred choice in an environment where a multitude of other reinforcers may exist. A practical application of this view is to understand the factors that make drug taking the preferred choice relative to the large number of alternative activities in the individual's surroundings. The goal of treatment might be to increase the availability of appealing alternatives such that drug taking becomes the nonpreferred activity. Thus, drug taking as a choice behavior may be examined in the context of qualitatively different, but

From the Department of Pharmacology, University of Michigan, Ann Arbor, Michigan.

Received for publication March 8, 1999; accepted April 4, 2000.

Supported by Grant AA-11424 from the United States Public Health Service.

Reprint requests: Keith Williams, Ph.D., 1301 MSRB III, Department of Pharmacology, University of Michigan, Ann Arbor, MI 48109-0632; Fax: 734-764-7118; E-mail: keithwil@umich.edu

Copyright (C) 2000 by the Research Society on Alcoholism. concurrently available, reinforcers (e.g., Carroll et al., 1991).

Choice procedures have been used to study the reinforcing properties of concurrently available reinforcers. The reinforcing effects of some orally delivered drugs were established by allowing animals concurrent access to drug (e.g., ethanol) and vehicle (e.g., water) while measuring variables such as response rate, reinforcer deliveries, and percentage of drug responding (Henningfield and Meisch, 1979; Meisch and Beardsley, 1975; Roehrs and Samson, 1981, 1982). When responding was greater for the drug than for the vehicle, the drug was considered to be a better reinforcer. Additionally, some orally delivered drugs will maintain greater responding at low or medium drug concentrations than at higher drug concentrations (Lemaire and Meisch, 1984; Stewart et al., 1996). Therefore, when examining number of responses or fluid deliveries, a low or medium drug concentration appears to be a more efficacious reinforcer than a high drug concentration.

Reinforcer efficacy may be assessed better by examining Alcohol Clin Exp Res, Vol 24, No 7, 2000: pp 980-986 
response strength (Nevin, 1974). Greater response strength is indicated by greater relative resistance to change in the number of drug deliveries produced by some experimental manipulation. For example, when various pentobarbital concentrations were concurrently available with water, the higher drug concentrations maintained more fluid deliveries than lower drug concentrations as the response requirements (fixed ratio [FR] values) for the fluids increased and when the interval between drug deliveries increased (Lemaire and Meisch, 1984, 1991). When different pentobarbital volumes were made concurrently available with water or other pentobarbital volumes, the higher drug volumes maintained more fluid deliveries than lower drug volumes as the FR values were increased (Lemaire and Meisch, 1985; Meisch and Lemaire, 1989). Thus, higher drug concentrations or volumes have greater reinforcing efficacy as indicated by the greater relative resistance to change in drug deliveries with increases in FR value, although higher drug concentrations and volumes may not maintain the highest amount of responding under all conditions. However, these studies could be expanded on. First, more experiments should be done to examine conditions in which the vehicle maintains more responding than the drug. In previously mentioned experiments, the researchers used those particular drug concentrations because they maintained greater responding when available concurrently with the water vehicle. Second, other orally self-administered drugs with different taste properties could be examined. For example, low concentrations of ethanol might maintain responding because of palatable taste properties (Meisch and Stewart, 1994). In an opposite manner, high ethanol concentrations maintain less responding than water when available concurrently with water (Stewart et al., 1996; Williams and Woods, 1999) perhaps due to aversive taste properties.

The reinforcing efficacy or strength of concurrently available reinforcers can be studied by using consumer demand theory. This conceptual framework has been used to analyze behavior in laboratory conditions and has been called "behavioral economics" (Allison 1979; Hursh, 1980, 1984). In behavioral economics, the consumption of a commodity can be analyzed as a function of its price. For example, when an animal is required to make responses for a reinforcer such as food, the price is the response requirement for each reinforcer delivery. A fundamental concept of consumer demand theory is the demand law. The demand law stipulates that, in general, total consumption of most commodities decreases as price increases (Allison, 1979). When consumption is plotted against price on logarithmic scales, the result is a graphic representation of the demand function called the demand curve. The demand curve yields two fundamental parameters: elasticity and level of demand (Hursh, 1984). The slope of the demand curve reflects the elasticity of demand (Allison, 1979; Hursh, 1980). The elasticity of a commodity with an increasing price is also called own-price elasticity. Own-price elasticity is de- fined as the proportional change in consumption of a reinforcer when there is a change in the price of that same reinforcer. Own-price elasticity is a continuum on which one end is elastic consumption, defined by steep demand slopes and own-price elasticities of $<-1.0$. On the other end, inelastic consumption is defined by shallow slopes and own-price elasticities of $>-1.0$. However, the slope of the overall demand curve can be misleading, because demand curves are usually nonlinear and therefore have mixed elasticities. For example, at low prices, the demand curve is usually inelastic; at high prices, the demand curve is usually elastic. Along with elasticity of demand, the level of demand also can be used to characterize the demand curve. The level of demand is the elevation of demand relative to its origin. For instance, an increase in demand level would cause a parallel shift upward of the demand curve. A decrease in demand level would cause a parallel shift downward of the demand curve. In behavioral economics, considerations of rate of responding are secondary to determinations of demand functions. However, rate of responding allows us to observe the behavioral output required to sustain a certain level of consumption, and rate of responding provides a basis for comparing another parameter, defined as $\mathrm{P}_{\max }$.

$P_{\max }$ values can be used to quantify reinforcing efficacy. $P_{\max }$ is an estimate of the commodity price at which maximal responding occurs and corresponds to the point on the demand curve where the slope becomes $<-1$ (Hursh, 1991; Hursh and Winger, 1995). Thus, $P_{\max }$ demarcates the boundary from inelastic to elastic demand. The $P_{\max }$ value is decreased when the level of demand decreases and/or elasticity of demand increases. A larger $\mathbf{P}_{\max }$ or a demand curve shift to the right would indicate an increase in reinforcing efficacy. For example, one study examined the slopes of demand curves for phencyclidine (PCP) when it was concurrently available with water (Carroll et al., 1991). Demand for PCP was more elastic when saccharin was the alternate fluid compared with when water was the alternate fluid. As a result, the $\mathrm{P}_{\max }$ for PCP was reduced or shifted to the left with concurrent saccharin access. Thus, $P_{\text {max }}$ may provide a quantitative method to analyze nonlinear demand functions.

The purpose of these experiments was to use behavioral economics to study the reinforcing efficacy or strength of ethanol and water in various preference conditions. For example, when ethanol fluid deliveries are greater than water fluid deliveries, ethanol appears to be the better reinforcer and may be called the "preferred fluid." However, when ethanol fluid deliveries are less than water fluid deliveries, water appears to be the better reinforcer and may be called the preferred fluid. We altered the response requirements for both fluids at ethanol concentrations where the ethanol fluid deliveries were greater than, equal to, or less than those of the concurrently available water. 


\section{METHODS}

Subjects

Subjects were four adult male rhesus monkeys, Macaca mulatta, weighing 6.5 to $9.2 \mathrm{~kg}$ and maintained at approximately $80 \%$ of their freefeeding weights. All of the monkeys had extensive experience responding for oral ethanol fluid deliveries. In these experiments, we followed the Guide for the Care and Use of Laboratory Animals (National Research Council, 1996).

\section{Apparatus}

The animal housing room was on a 12 hr light/dark cycle (lights on at $0630 \mathrm{hr}$, lights off at $1830 \mathrm{hr}$ ). The monkeys were housed in individual cages measuring $64 \mathrm{~cm} \times 72 \mathrm{~cm} \times 85 \mathrm{~cm}$ high. A fluid-delivery panel, similar to that used in other studies (Meisch et al., 1975; Williams et al., 1998), was attached to one wall of each cage during daily sessions. Holes were cut in the cage wall so that two brass spouts on the fluid-delivery panel protruded into the cage $50 \mathrm{~cm}$ from the floor. A stimulus light that could be illuminated red or green was located $3 \mathrm{~cm}$ above each spout. The drinking solutions were contained in $1000 \mathrm{ml}$ plastic bottles attached to the back of the panel. Plastic tubing connected each bottle to the spout valve. The fluid containers were elevated so that the liquid was gravity-fed to the spout valve, and delivery was controlled by a solenoid switch. Contact with either spout closed an electrical circuit (drinkometer), and a response was recorded. The stimulus light above the spout flashed when contact was made with the spout. When the reinforcement schedule was completed, the solenoid was opened for approximately $0.1 \mathrm{sec}$ so that a fluid volume of $0.5 \mathrm{ml}$ was delivered into the cage. In some observations, the monkeys would suck on the spout at the time the solenoid was open and thus receive more solution volume than was intended. To avoid this problem, extra holes were put into the spout such that a monkey that sucked on the spout would receive air rather than extra solution. Solutions were measured after the session by using graduated cylinders to confirm delivery amounts. The experiments were controlled and the data recorded by using IBM PCjr microcomputers located in a room adjacent to the housing room.

\section{Procedure}

Experimental sessions were conducted 7 days a week. Each session lasted $2 \mathrm{hr}$, during which the animal could respond and obtain either ethanol or water. Ethanol was available under a red stimulus light, and water was available under a green stimulus light. The monkeys were reinforced with $0.5 \mathrm{ml}$ of fluid for every four mouth contacts on the spout (FR 4). Water was always available from one of the spouts, and the animals were fed after the session.

We determined an ethanol concentration-effect curve in these monkeys before any changes in FR values. The ethanol concentrations were tested in an ascending order from $1 \%$ to $32 \%$. Each concentration was determined for 6 to 8 days before increasing to the next concentration. While the ethanol concentration was still set at $32 \%$, the FR was increased in the following order: 4, 8, 16, 32, 64. After completion at FR 64, the FR was reset to FR 4 to replicate the original baseline. Each FR was tested for 6 to 8 days before increasing to the next FR value. Then, $2 \%$ ethanol was tested in a similar manner, followed by $8 \%$ ethanol. We increased the FRs in an ascending order to avoid a reduction in responding due to a transition from a small FR schedule to a large FR schedule. For example, if there were an abrupt change from FR 4 to FR 64, a monkey might cease responding due to lack of reinforcement before 64 responses were emitted.

\section{Drugs}

We prepared ethanol solutions by mixing appropriate volumes of $95 \%$ w/v ethanol and tap water. Thus, a $2 \%$ ethanol solution consisted of $20 \mathrm{~g}$ of ethanol in $1000 \mathrm{ml}$ of water.

\section{Data Analysis}

Each monkey's average fluid deliveries, responses, and ethanol intake in grams per kilogram body weight were used to calculate the mean and standard error of the mean for the group of monkeys. Although each experimental manipulation was maintained for 6 to 8 days, we used only the data from the last 3 days of each manipulation to calculate each monkey's average to reduce the variability that follows a change in experimental conditions. We calculated the percentage of ethanol-maintained responding by dividing the number of responses for ethanol by the total number of responses. The data are presented as the mean and standard error of the mean for the group data. To directly compare the ethanol and water fluid deliveries and responding, the unit price for ethanol and water was considered to be functionally equivalent to the FR.

We analyzed the data for the ethanol concentration-effect curve by using a two-way repeated measures analysis of variance (ANOVA). We tested for an effect of fluid (two levels: ethanol and water), an effect of ethanol concentration (five levels: $2 \%, 4 \%, 8 \%, 16 \%$, and $32 \%$ ), and an interaction effect. For individual comparisons, we conducted a Tukey's test for honestly significant difference (HSD). For the FR manipulations at $2 \%, 8 \%$, and $32 \%$ ethanol, we also analyzed the fluid delivery and responding data by using a two-way repeated measures ANOVA. We tested for a fluid effect (two levels: ethanol and water), an FR effect (six levels: original FR 4, replication FR 4, FR 8, FR 16, FR 32, FR 64), and an interaction effect. For individual comparisons, a Tukey's HSD test was conducted on the interaction effect. The ethanol intake and percentage of ethanol responding data were analyzed using one-way repeated measures ANOVA. For individual comparisons, a Tukey's HSD test was conducted. For the analysis involving FR changes, the original FR 4 and the replication FR 4 were considered as different levels so that they could be compared to each other with the Tukey's HSD test. For all significant effects, $p<0.05$.

$P_{\max }$ values were obtained using the method described by Hursh (1991). The equation was as follows: $\mathrm{P}_{\max }=(1+b) / a$, where $a$ and $b$ are parameters derived from an equation estimating demand:

$$
\ln (Q)=\ln (L)+b(\ln P)-a(P)
$$

In the preceding equation, consumption $(Q)$ is stated as a function of initial level of demand at minimal price $(L)$ and current price $(P)$. Consumption is also affected by the initial slope of the demand curve at minimal price $(b)$ and the acceleration or increase in slope of the demand curve with increases in price $(a)$. We calculated the beta coefficients for $a$ and $b$ by using Prism (GraphPAD Software, San Diego, CA). The parameters were estimated with the raw fluid delivery data as consumption and the FR values as price. The data from the replication FR 4 conditions were not included when estimating the parameters.

\section{RESULTS}

\section{Concentration-Effect Curve}

The ethanol concentration-effect curve is shown in Fig. 1 (upper panel). Ethanol, $2 \%$ and $4 \%$, maintained more fluid deliveries than the concurrently available water. At $8 \%$ and $16 \%$ ethanol, the ethanol and water fluid deliveries were approximately equal. At the highest ethanol concentration tested, $32 \%$, water maintained greater fluid deliveries than ethanol. The effect of fluid was not significant $[F(1,3)=$ 5.6]. There was a significant effect of concentration $[F(4,12)=6.1]$. Although the interaction effect was significant $[F(4,12)=16.4]$, the Tukey's HSD test revealed that the only significant difference between ethanol and water fluid deliveries was at $2 \%$ ethanol. Ethanol intake (Fig. 1, lower panel) was between 1 and $2 \mathrm{~g} / \mathrm{kg}$ across all concen- 

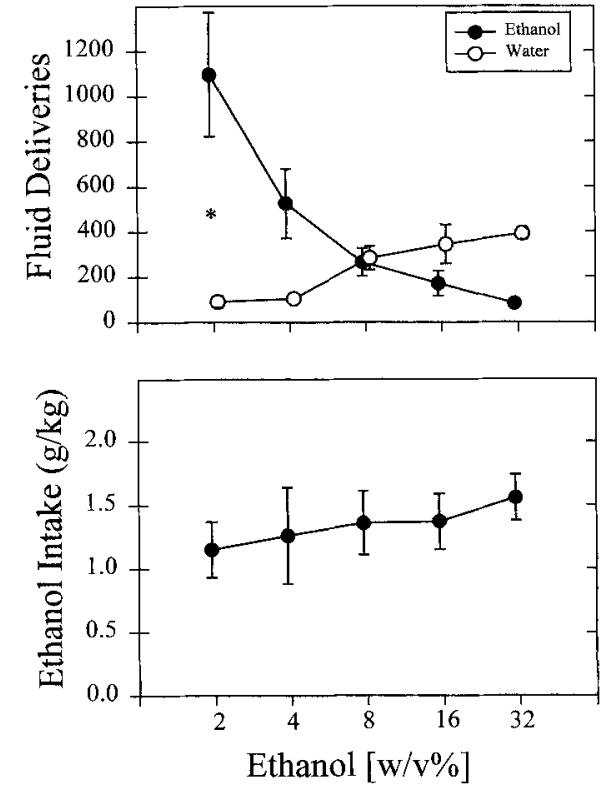

Fig. 1. (Top panel) Average number of fluid deliveries for ethanol (filied circies) and concurrently available water (open circles) as the concentration of ethanol varied from $2 \%$ to $32 \%$. (Bottom panel) Average intake in grams per kilogram body weight as ethanol concentration varied (filled circles). The points represent the overall average with the standard error $(n=4)$. "Significant difference $(0<$ 0.05 ) between ethanol and water at that particular ethanol concentration.

trations tested. There were no statistically significant differences in ethanol intake.

\section{Effect of Increasing Fixed Ratio Values}

When the FR increased during access to $2 \%$ ethanol, the analysis of fluid deliveries, plotted as demand curves in Fig. 2 (upper left panel), showed a significant effect of FR $[F(5,15)=10.9]$ and a significant interaction effect $[F(5,15)=3.2]$. The Tukey's HSD test showed that ethanol fluid deliveries at FR 16 and higher were decreased below the ethanol fluid deliveries of the FR 4 conditions. Although the fluid effect was not significant, when we compared the ethanol and water at each FR value, the ethanol fluid deliveries were greater than the water fluid deliveries at the original FR 4 condition but not at the replication FR 4 condition. Water fluid deliveries were not significantly affected by the FR increases. For the responding data (Fig. 2 , lower left panel), the main effects and the interaction effect were not significant. However, the Tukey's HSD test showed that the responding for ethanol was greater than the responding for water at the FR 16 condition. When compared with the FR 4 condition, the ethanol intake in grams per kilogram body weight (Fig. 2, upper right panel) was decreased at FR 16 and higher FRs [main effect of FR, $F(5,15)=7.9]$. When total responding was expressed a percentage of ethanol-maintained responding, $87 \%$ of all responses were directed toward the ethanol spout in the FR 4 condition. Increasing the FR value had no effect on the percentage of ethanol responding. The $\mathrm{P}_{\text {max }}$ values coincide with the point where the vertical lines (solid line, ethanol;
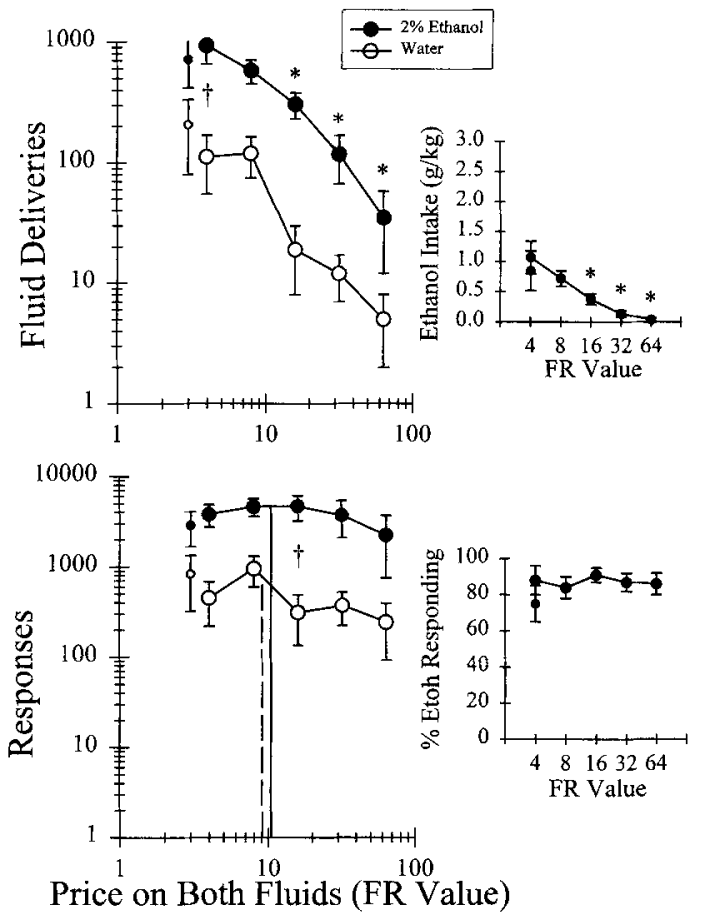

Fig. 2. (Top left panel) Average number of fluid deliveries of $2 \%$ ethanol (filled circles) and concurrently available water (open circles) at different FR values. (Bottom left panel) Average number of responses for $2 \%$ ethanot (filled circles) and water (open circles) at different FR values (FR 4, FR 8, FR 16, FR 32, FR 64). Vertical lines represent $P_{\max }$ values for $2 \%$ ethanol (solid) and water (dashed). (Top right panel) Average ethanol intake at different $F R$ values. (Bottom right panel) Average percentage of responding for $2 \%$ ethanol. Detached symbols in each graph represent a replication at FR 4 . All points represent the overall average with the standard error $(n=4)$. *Significant difference $(p<0.05)$ from the original FR 4 within fluid. †Significant difference $(p<0.05)$ between ethanol and water at that particular FR value.

dashed line, water) cross the $x$ axis in the lower left panel of Fig. 2. The vertical lines show that when $2 \%$ ethanol and water were available concurrently, the $\mathrm{P}_{\max }$ values for ethanol and water were similar (actual $P_{\max }$ values in Table 1).

When the FR was increased during access to $8 \%$ ethanol, shown in upper left panel of Fig. 3, the fluid deliveries were not different for ethanol compared with water. Although the fluid main effect and the interaction effect were not significant, there was a main effect of $\operatorname{FR~}[F(5,15)=11.7]$. There were no significant individual comparisons. For the responding data (Fig. 3, lower left panel), the interaction of fluid and FR was significant $[F(5,15)=2.9]$. When the ethanol and water were compared at each $F R$ value, the number of responses for $8 \%$ ethanol was greater than that for water at FR 32 and FR 64. Compared with the FR 4 condition, ethanol intake (Fig. 3, upper right panel) was reduced at FR values higher than FR 8 [main effect of FR, $F(5,15)=16.8]$. The percentage of ethanol-maintained responding (Fig. 3, lower right panel) was not significantly affected by increased FR values. The vertical lines in the lower left panel of Fig. 3 show that the $P_{\max }$ value for ethanol (solid line) was greater than the $\mathrm{P}_{\max }$ value for water (dashed line) when $8 \%$ ethanol was available concurrently with water (actual $P_{\max }$ values in Table 1). 

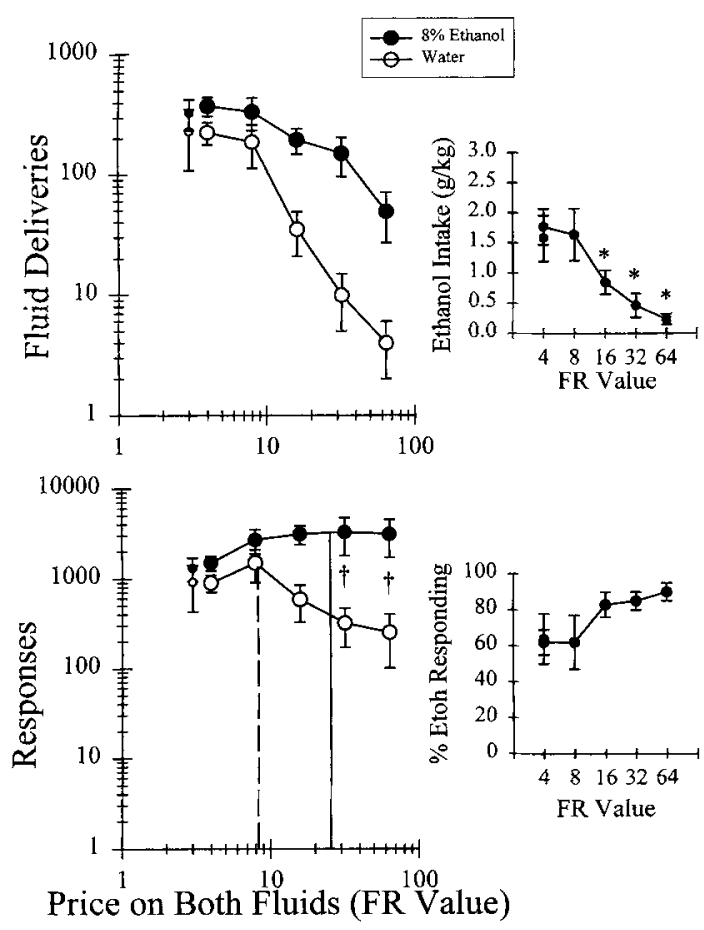

Fig. 3. Data for $8 \%$ ethanol and concurrently available water shown in the same format as Fig. 2.

In the upper left panel of Fig. 4, the fluid delivery data for $32 \%$ ethanol and water are plotted as demand curves. There was a significant effect of fluid $[F(1,3)=22.1]$ and FR $[F(5,15)=62.8]$ and an interaction effect $[F(5,15)=$ 54.5]. Increases in FR values failed to significantly reduce the fluid deliveries of ethanol. Water fluid deliveries at FR 8 and higher were significantly less than the water fluid deliveries at the FR 4 conditions. At the original FR 4, the replication FR 4, and FR 8 conditions, water fluid deliveries were greater than those of ethanol. As the FR value increased, the number of responses (Fig. 4, lower left panel) for water decreased such that the responses for water at FR 64 were less than the responses for water at FR 4 [interaction effect, $F(5,15)=14.9$ ]. In an opposite manner, ethanol-maintained responding increased as FR increased, such that the ethanol-maintained responding at FR 32 and FR 64 was greater than the ethanol-maintained responding at FR 4 . When we compared the ethanol and water at each FR value, the number of responses for water was greater than number of responses for ethanol at the original FR 4 condition; the responses for ethanol were greater than those for water at FR 32 and FR 64 . However, there was no difference between the responses for ethanol and water at the replication FR 4 condition. Ethanol intake (Fig. 4, upper right panel) decreased as FR increased [main effect of FR, $F(5,15)=12.8$ ]. At FR 64, ethanol intake was significantly less than at FR4. The percentage of ethanolmaintained responding (Fig. 4, lower right panel) increased as the $F R$ value increased $[F(5,15)=41.9]$. When compared with the FR 4 condition, the percentage of ethanolmaintained responding was increased at FR 16, FR 32, and
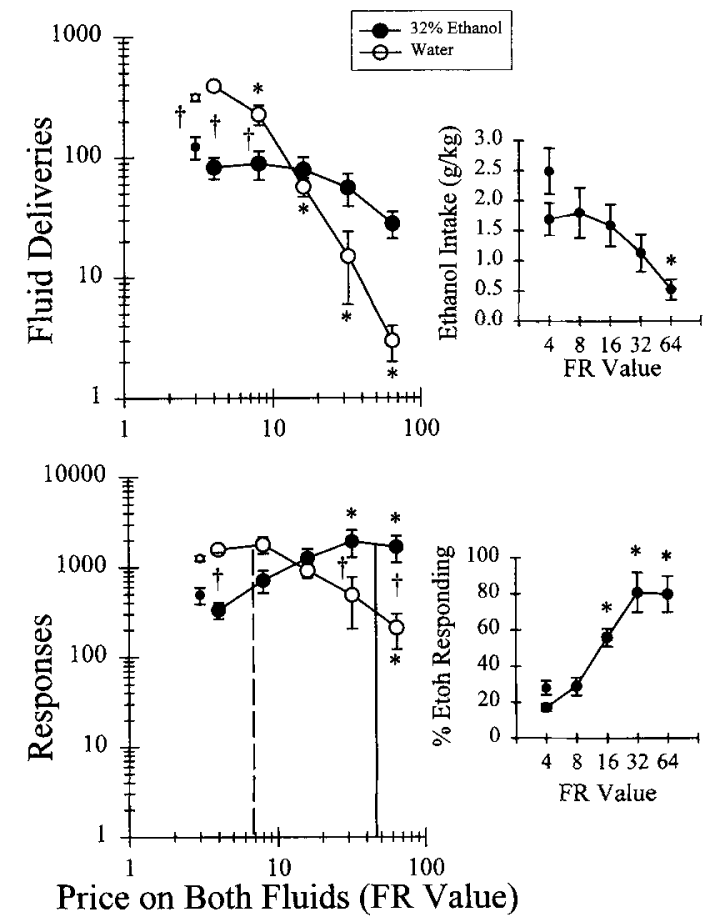

Fig. 4. Data for $32 \%$ ethanol and concurrently available water shown in the same format as Figs. 2 and 3.

FR 64. The vertical lines in the lower left panel of Fig. 4 indicate that the $P_{\max }$ value for ethanol (solid line) was much greater than the $\mathrm{P}_{\max }$ value for water (dashed line) when $32 \%$ ethanol was available concurrently with water (actual $P_{\max }$ values in Table 1).

\section{Behavioral Economic Analysis}

The parameter estimates for the demand curve are shown in Table 1. The parameter $L$ represents the initial level of demand at minimal price (fluid deliveries at the original FR 4). The parameter $a$ represents the "acceleration" in slope of the demand curve with increases in price. At each ethanol concentration, the acceleration for the water demand curve was greater than the acceleration for the ethanol demand curve, which indicates that the water consumption decreased more rapidly than the ethanol consumption as the FR increased. The acceleration for ethanol was smaller at higher ethanol concentrations, which means

Table 1. Demand Equation Parameter Estimates, $P_{\max }$, and $R^{2}$ Values for Ethanol and Water at Various Ethanol Concentrations

\begin{tabular}{lrrrrr}
\hline \multicolumn{1}{c}{ Solution } & \multicolumn{1}{c}{$L^{a}$} & $a^{a}$ & $b^{a}$ & \multicolumn{1}{c}{$\mathbf{P}_{\max }{ }^{b}$} & $R^{2 c}$ \\
\hline Ethanol 2\% & 936 & 0.1238 & 0.3038 & 10.5 & 0.97 \\
Water & 112 & 0.1748 & 0.6041 & 9.2 & 0.91 \\
Ethanol 8\% & 376 & 0.0420 & 0.0831 & 25.8 & 0.95 \\
Water & 225 & 0.1969 & 0.6122 & 8.2 & 0.98 \\
Ethanol 32\% & 83 & 0.0241 & 0.1129 & 46.2 & 0.99 \\
Water & 392 & 0.2514 & 0.7185 & 6.8 & 0.99 \\
\hline
\end{tabular}

${ }^{a}$ From the demand equation $\ln (Q)=\ln (L)+b(\ln P)-a(P) ;{ }^{b}$ From the equation $\mathbf{P}_{\max }=(1+b) / a ;{ }^{c}$ Estimate of fit of the demand equation to each curve. 
that ethanol consumption decreased more slowly as the FR increased at higher ethanol concentrations. In contrast, the acceleration for water was larger when higher ethanol concentrations were concurrently available, which means that the water consumption decreased more rapidly as the FR increased when higher ethanol concentrations were concurrently available. The parameter $b$ represents the initial slope of the demand curve at minimal price. When the initial slopes are negative or close to zero, the elasticity differences are manifest in changes in $a$ (Hursh, 1991). The initial slope for all curves was $<1 . P_{\max }$ demarcates the boundary from inelastic to elastic demand. As the ethanol concentration increased, the ethanol $\mathrm{P}_{\max }$ increased. For water, the $\mathrm{P}_{\max }$ values were similar to each other regardless of which ethanol concentration was concurrently available. The value $R^{2}$ represents the variance in the data that is accounted for in the equation. The $R^{2}$ can also be considered an estimate of the curve fit to the demand equation. The fit of the demand equation to the curves was good. All $R^{2}$ values were between 0.91 and 0.99 , which means that the equation accounted for approximately $91 \%$ to $99 \%$ of the variance in the data.

\section{DISCUSSION}

When ethanol was available concurrently with water, responding for ethanol was more resistant to increases in response requirement even when the ethanol fluid deliveries were equal to or less than the concurrently available water. For example, at the $8 \%$ concentration, ethanol and water fluid deliveries were similar at FR 4. As the FR value increased, responding for ethanol increased and responding for water decreased. When $32 \%$ ethanol was available with water concurrently, the ethanol fluid deliveries were less than water fluid deliveries at FR 4. As the FR value increased, responding for ethanol increased and responding for water decreased. As ethanol concentration increased, the slopes of the ethanol demand curves decreased (smaller acceleration values) and the $P_{\max }$ value was shifted to the right for ethanol. The slopes of the water demand curves increased (larger acceleration values) and the $P_{\max }$ value remained the same as the ethanol concentration increased.

Reinforcers should be evaluated by using other methods in addition to measuring preference. Some studies manipulated FR, body weight, and alternative fluids to examine ethanol preference and found it to be an inappropriate measure of ethanol's reinforcing efficacy (Roehrs and Samson, 1981; Samson et al., 1982). The studies by Lemaire and Meisch (Lemaire and Meisch, 1984, 1985, 1991; Meisch and LeMaire, 1989) show that higher drug concentrations or volumes have greater reinforcing efficacy even though they may not maintain the highest number of fluid deliveries under all conditions. We decided to extend on the previous research by altering the economic parameters in a condition where the drug maintains responding equal to or less than the water vehicle. Although the ethanol fluid deliveries were equal to or less than those of water when ethanol was $8 \%$ or $32 \%$, the reinforcing efficacy of ethanol was more clearly displayed when the response requirements were increased. Thus, when examining the ability of drugs to act as reinforcers in a concurrent access situation, it is important to consider measuring preference over a broad range of drug concentrations and economic conditions.

Behavioral economics provides parameters that can be used to quantitatively assess reinforcer efficacy. When the FR values increase, the economic conditions under which the fluids are available also change. These economic changes can be assessed by using the demand curve. The slope of the demand curve is a measure of that commodity's elasticity or resistance to increases in price. However, demand curve slopes are usually nonlinear and therefore should not be evaluated with simple linear regression. Hursh (1991) proposed an equation that provides other measurable parameters such as the price at which maximal responding occurs $\left(\mathrm{P}_{\max }\right) . \mathrm{P}_{\max }$ for oral reinforcers is affected by a variety of environmental conditions that may alter the ability of solutions to serve as reinforcers. For instance, food deprivation increased $P_{\max }$ for ethanol and PCP (Rodefer et al., 1996). When time available to respond for ethanol or PCP was reduced, $\mathrm{P}_{\max }$ increased, but only when water, not saccharin, was concurrently available (Carroll and Rodefer, 1993; Carroll et al., 1995). Pretreatment with the partial $\mu$-agonist buprenorphine decreased the $\mathbf{P}_{\max }$ for PCP and saccharin (Rawleigh et al., 1996). In our study, changing the ethanol concentration changed the $\mathrm{P}_{\max }$ for ethanol but not for water. The $\mathrm{P}_{\max }$ for ethanol was larger at higher ethanol concentrations. These results indicate that the reinforcing efficacy of ethanol, as measured by $\mathbf{P}_{\text {max }}$, depends on the ethanol concentration. Higher ethanol concentrations have greater reinforcing efficacy than lower ethanol concentrations even when the number of ethanol fluid deliveries is less than that of the concurrently available water. Therefore, $\mathbf{P}_{\max }$ and its corresponding $a$ value may be better quantitative measures of reinforcer efficacy than preference measures or the slope of demand curves determined by linear regression.

Ethanol's reinforcing efficacy probably is determined by ethanol's pharmacological effects. For example, ethanol intake in grams per kilogram remained constant as ethanol concentration increased during the ethanol concentrationeffect curve even as the number of ethanol fluid deliveries decreased. Some have concluded that high ethanol concentrations may have an aversive taste and therefore maintain less fluid deliveries than lower, more palatable ethanol concentrations (Meisch and Stewart, 1994). Although the ethanol fluid deliveries were less than the water fluid deliveries at FR 4, responding for ethanol increased as the FR value increased. The higher responding for ethanol allowed the ethanol fluid deliveries and intake at FR 8, FR 16, and FR 32 to remain similar to those at FR 4. Other studies have shown that high drug concentrations maintain less fluid deliveries than low concentrations when offered con- 
currently with water, but when both high and low concentrations are offered concurrently, the higher concentration maintains more fluid deliveries (Meisch and LeMaire, 1988; Meisch et al., 1996). Thus, the pharmacological effects of ethanol may contribute to the changes in responding that result from altering the economic conditions in which the solutions are available.

Some potential confounds remain to be addressed. For instance, the FR values were increased in an ascending, rather than random, order. Additionally, the ethanol concentrations were not presented randomly. The lack of random presentation of FR values and ethanol concentrations may have altered the results. We tried to control for an effect of the nonrandom FR presentation by replicating the FR 4 condition after completion of the FR increases. Additionally, in a couple of cases the original and replication FR 4 conditions did not agree with each other. For example, at $2 \%$ ethanol (Fig. 2), there was a significant difference between the ethanol and water fluid deliveries in the original FR 4 condition but not in the replication FR 4 condition. Also, at $32 \%$ ethanol (Fig. 4), the responding for water was significantly greater than that for ethanol at the original FR 4 condition but not the replication FR 4 condition. These differences between original and replication FR 4 conditions may have resulted from the particular order of the experimental manipulations. However, in general, the data from the replication FR 4 condition are similar to the data from the original FR 4 condition. So, it is also likely that the statistics were affected by the variability in the data because of the small number of subjects.

Overall, this study showed that the reinforcing efficacy of ethanol, as measured by behavioral economic parameters, increased as ethanol concentration increased. The reinforcing effects of ethanol should be studied in a variety of preference and economic conditions. And finally, ethanol's pharmacological effects may mediate ethanol consumption even when ethanol is the nonpreferred fluid.

\section{ACKNOWLEDGMENT}

We thank James Liang for technical and theoretical contributions.

\section{REFERENCES}

Allison J (1979) Demand economics and experimental psychology. Behav Sci 24:403-417.

Carroll ME, Carmona GN, May SA (1991) Modifying drug-reinforced behavior by altering the economic conditions of the drug and a nondrug reinforcer. J Exp Anal Behav 56:361-376.

Carroll ME, Rodefer JS (1993) Income alters choice between drug and an alternative nondrug reinforcer in monkeys. Exp Clin Psychopharmacol 1:110-120.

Carroll ME, Rodefer JS, Rawleigh JM (1995) Concurrent selfadministration of ethanol and an alternative nondrug reinforcer in monkeys: Effects of income (session length) on demand for drug. Psychopharmacology 120:1-9.

Henningfield JE, Meisch RA (1979) Ethanol drinking by rhesus monkeys with concurrent access to water. Pharmacol Biochem Behav 10:777-782.
Hursh SR (1980) Economic concepts for the analysis of behavior. J Exp Anal Behav 34:219-238.

Hursh SR (1984) Behavioral economics. J Exp Anal Behav 42:435-452.

Hursh SR (1991) Behavioral economics of drug self-administration and drug abuse policy. J Exp Anal Behav 56:377-393.

Hursh SR, Winger G (1995) Normalized demand for drugs and other reinforcers. J Exp Anal Behav 64:373-384.

Jaffe J (1990) Drug addiction and drug abuse, in The pharmacological Basis of Therapeutics (Goodman A, Rall T, Nies A, Taylor P eds), pp 522-573. Pergamon, New York.

Lemaire GA, Meisch RA (1984) Pentobarbital self-administration in rhesus monkeys: Drug concentration and fixed-ratio size interactions. J Exp Anal Behav 42:37-49.

Lemaire GA, Meisch RA (1985) Oral drug self-administration in rhesus monkeys: Interactions between drug amount and fixed-ratio size. J Exp Anal Behav 44:377-389.

Lemaire GA, Meisch RA (1991) Relative reinforcing effects of pentobarbital solutions orally self-administered by rhesus monkeys under fixed ratio and signalled DRL schedules. Psychol Rec 41:551-583.

Meisch RA, Beardsley P (1975) Ethanol as a reinforcer for rats: Effects of concurrent access to water and alternate positions of water and ethanol. Psychopharmacologia (Berl.) 43:19-23.

Meisch RA, Henningfield J, Thompson T (1975) Establishment of ethanol as a reinforcer for rhesus monkeys via the oral route: Initial results. Adv Exp Med Biol 59:323-342.

Meisch RA, Lemaire GA (1989) Oral self-administration of pentobarbital by rhesus monkeys: Maintenance of behavior by different concurrently available volumes of drug solution. J Exp Anal Behav 52:111-126.

Meisch RA, Stewart RB (1994) Ethanol as a reinforcer: A review of laboratory studies of non-human primates. Behav Pharmacol 5:425440.

Meisch RA, Stewart RB, Wang N-S (1996) Orally delivered methadone as a reinforcer for rhesus monkeys: The relationship between drug concentration and choice. Pharmacol Biochem Behav 54:547-554.

National Research Council (1996) Guide for the Care and Use of Laboratory Animals. National Academy Press, Washington, D.C.

Nevin JA (1974) Response strength in multiple schedules. J Exp Anal Behav 21:389-408.

Rawleigh JM, Rodefer JS, Hansen JJ, Carroll ME (1996) Combined effects of buprenorphine and an alternative nondrug reinforcer on phencyclidine self-administration in rhesus monkeys. Exp Clin Psychopharmacol 4:68-76.

Rodefer JS, DeRoche KK, Lynch WA, Carroll ME (1996) Feeding conditions alter the demand for phencyclidine and ethanol: A behavioral economic analysis. Exp Clin Psychopharmacol 6:61-67.

Roehrs TA, Samson HH (1981) Ethanol reinforced behavior assessed with a concurrent schedule. Pharmacol Biochem Behav 15:539-544.

Roehrs TA, Samson HH (1982) Relative responding on concurrent schedules: Indexing ethanol's reinforcing efficacy. Pharmacol Biochem Behav 16:393-396.

Samson HH, Roehrs TA, Tolliver GA (1982) Ethanol reinforced responding in the rat: A concurrent analysis using sucrose as the alternate choice. Pharmacol Biochem Behav 17:333-339.

Stewart RB, Bass AA, Wang N-S, Meisch RA (1996) Ethanol as an oral reinforcer in normal weight rhesus monkeys: Dose-response functions. Alcohol 13:341-346.

Vuchinich RE, Tucker JA (1988) Contributions from behavioral theories of choice to an analysis of alcohol abuse. J Abnormal Psych 97:181-195.

Williams KL, Winger G, Pakarinen ED, Woods JH (1998) Naltrexone reduces ethanol- and sucrose-reinforced responding in rhesus monkeys. Psychopharmacology 139:53-61.

Williams KL, Woods JH (1999) Naltrexone reduces ethanol- and/or waterreinforced responding in rhesus monkeys: Effect depends upon ethanol concentration. Alcohol Clin Exp Res 23:1462-1467. 